\title{
Employee Safety and Performance in Quick Service Restaurant during New Normal
}

\author{
Dr. K. Meenatchi Somasundari ${ }^{1}$, Dr. M. Vidya ${ }^{2}$ \\ ${ }^{1,2}$ Assistant Professor, Department of Management Science, Sri Krishna Arts and Science College, Coimbatore.
}

\begin{abstract}
Safety sounds in the employee's world who have direct linkage with the public. This creates the responsibility of the business entity irrespective of nature of business to ensure that every individual has to learn organizational safety values. Unsafe work environments have clear consequences for both individuals and the organization, henceforth some organization replace the revoked safety programs with more innovative ideas during this New Normal period. It would also help industry to ensure that employees take protection against unsafe practices during covid-19 situation. Employees of Quick Service Restaurant industries can remain motivated and ensured safety at their workplace, will enrich their performance. The study conducted through questionnaire survey with 74 respondents and judgmental sampling method is used to select sample respondents. Hence his paper is about the employees' safety and performance in Quick Service Restaurant (QSR) industry based on employee's opinion. The researchers concluded that to include clear and concise plans for safety in the organization addressing how to do the work safely by wearing masks, sanitizing themselves before having contact with another individual; maintain social distancing in these new normal plays a significant role in an individual's health and behaviour.
\end{abstract}

Key words : Safety, Quick service, Social Distancing

\section{INTRODUCTION}

Irrespective of the nature of business, it is the responsibility of the employer to ensure the safetyand healthy working climate. Regardless of risk, with a view to minimize there is a need to set safety standards. An efficient productive team is always a safety one. One employee acting irresponsibly cannot only hurt themselves, but other employees as well. The primary reason that employees must understand their role in ensuring safe and healthy working climate. More than $50 \%$ of sales in the restaurant sector by Quick Service restaurant (QSR), dominated by fast casual food style to attain market share. The QSR (McDonald's Corporation, KFC (short for Kentucky Fried Chicken), Domino's,Subway (also known as Doctor's Associates Inc, Pizza Hut) have a consistent, simple, nice ambience and grab a tray to sit and eat. Since safety sounds in the employee's world who have direct linkage withthe public. This creates the responsibility of the business entity irrespective of nature of business to ensure that every individual has to learn organizational safety values. Unsafe work environments have clear consequences for both individuals and the organization, henceforth some organization replace therevoked safety programs with more innovative ideas during this New Normal period. It would also helpindustry to ensure that employees take protection against unsafe practices during covid-19 situation.

\section{RESEARCH DESIGN}

The Research design adopted in this study is descriptive research design. The study conductedthrough questionnaire surveys with 74 respondents and judgmental sampling method is used to select sample respondents. The sample respondents are the employees in Quick Service Restaurant (McDonald's Corporation, KFC (short for Kentucky Fried Chicken), Domino's, Subway (also known as Doctor's Associates Inc, Pizza Hut).

\subsection{Objectives of the study}

- A study on QSR industry on employee safety and performance during COVID New Normal with the Perception of employee commitment to safety and to find the impact of employee safety and performance in QSR industry.

\subsection{Rationale of the study}

For Quick Service Restaurant, safety and health measures plays a crucial concern for the employees. Higher morale and performance to increase productivity is possible if the organization focuson the safety protocols. Todays' society demands every business entity to truly cares about health and well -being of the employees. The unsafe practices during Covid brings negative consequences. Hencean attempt has been made by the researchers to study about the safety measures of employees in QuickService Restaurant and the related performance in enhancing productivity. 
DOI: 10.17148/IARJSET.2021.8947

3. ANALYSIS AND INTERPRETATION:

Table - Employees Awareness and Agreeable

\begin{tabular}{lllll}
\multicolumn{2}{c}{ Awareness } & & Agreeable & Marital status \\
\hline Awareness & Pearson Correlation & 1 & $.862^{* *}$ & $-.666^{* *}$ \\
\cline { 2 - 5 } & Sig. (2-tailed) & & .000 & .000 \\
\cline { 2 - 5 } Agreeable & $\mathrm{N}$ & 74 & 74 & 74 \\
\cline { 2 - 5 } & Pearson Correlation & $.862^{* *}$ & 1 & $-.798^{* *}$ \\
\cline { 2 - 5 } Marital status $(2-t a i l e d)$ & .000 & 74 & .000 \\
\hline & $\mathrm{N}$ & 74 & $-.798^{* *}$ & 1 \\
\hline & Pearson Correlation & $-.666^{* *}$ & .000 & \\
\hline & Sig. (2-tailed) & .000 & 74 & 74 \\
\hline
\end{tabular}

**. Correlation is significant at the 0.01 level (2-tailed).

From the analysis, it is inferred that the safety and health standards of QSR industries keep informed on regular and it is agreed by the employees. The safeness during covid ensures enhancementin the performance of the employees, so that the productivity improve thereby. The correlation table shows that there is no significant difference among employees view on safety awareness during covid.

\section{SUGGESTIONS:}

Being direct conduct with the people the restaurant employees must be conscious enough to handling the food service to the public. Conducting regular inspections to check if employee is out frompotential dangers and must be careful in this covid-19 situation. When an unsafe work situation is foundout, the employees who are affected by covid-19 should know to report to the higher authorities about the issue as soon as it's found. Maintaining social distancing and getting a regular check-up of the employees will keep all the risks away by wearing masks, sanitizing themselves before having a contact with the customers.

\section{CONCLUSIONS}

It is concluded that the Employer and the organization has a responsibility to ensure that their employees are safe at work, and so may institute regulations and policies to ensure this. It is now the responsibility of the employee to make certain that they follow these rules in this covid-19 situation. The key to the success of a safety and health plan is to see it as a part of the business operation and to see it reflected in the day-today operations. Protecting people on the job is in everyone's best interest - our economy, our communities, our fellow workers and our families. Employee safety and productivityplay a major role in every organization. Each workplace is different and dynamic. Therefore, the strategy used to effectively manage the human resource should also be different and dynamic. This strategy should include clear and concise plans for safety in the organization addressing how to do thework safely by wearing masks, sanitizing themselves before having contact with another individual; maintain social distancing in these COVID New Normal days.

\section{REFERENCES:}

- www.dominos.com/

- $\quad$ https://online.kfc.co.in/contact-us

- $\quad$ https://www.linkedin.com/company/mcdonald\%27s-corporation

- https://www.subway.com/

- $\quad$ https://www.pizzahut.co.in/

- $\quad$ Life-cycle working time and nonstandard work ( p. 371 ). Kalamazoo, MI: W.E. Upjohn Institute for Employment Research “A case study on Occupational health and safety research survey"

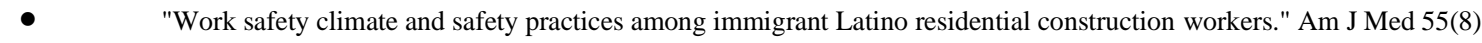

- $\quad$ "Multilevel safety culture and climate survey for assessing new safety Program." Journal of Construction Engineering and Management

- https://www.elcosh.org/document/4356/d001611/Safety\%2BCulture\%2Band

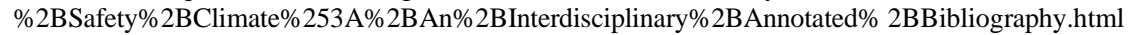

